\begin{abstract}
There has been widespread concern over the lack of preparedness of students making the transition from school to university mathematics and the changing profile of entrants to mathematical subjects in higher education has been well documented. In this paper, using documentary analysis and data from an informal case study, we argue the antecedents of this changed profile in the general shift across all subjects to a more utilitarian higher education, alongside the more specific changes in A-level mathematics provision which have been largely market driven. Our conclusions suggest that, ironically, changes put in place to make mathematics more widely useful may result in it losing just those features that make it marketable.
\end{abstract}




\title{
Changing Patterns of Transition from School to University Mathematics
}

\author{
Celia Hoyles, Kate Newman and Richard Noss \\ Mathematical Sciences Group, Institute of Education, \\ University of London \\ 20 Bedford Way, London WC1H OAL
}

During the last few years the role of higher education in the U.K. has changed dramatically. Not only have the numbers entering higher education increased substantially but the aims and objectives of a university degree have undergone significant change. These are summed up in the terms of reference for The National Committee of Inquiry into Higher Education, chaired by Dearing (1997) which state that: 'There should be maximum participation in initial Higher Education by young and mature students and in lifetime learning by adults, having regard to the needs of individuals, the nation and the future labour market....learning should be increasingly responsive to employment needs and include the development of general skill, widely valued in employment' (summary report, p.5).

Not long ago the situation was very different, with no more than $5 \%$ of 18 -year olds choosing to further their studies, many of whom chose a subject for reasons entirely unconnected with their future career path. This was, of course, a time during which the mere possession of a degree did afford access to a range of occupations, often with little relationship between the requisite skills for the job and the subject of the degree. All this has changed, and many more 18 year olds (over $30 \%$ and rising) are now deciding to continue their studies after compulsory education, with the expectation that it will enhance their employment opportunities.

The demographic and sociological trends which form a background to these changes are manifold and consideration of them lies outside our area of expertise. Nevertheless, one facet of these changes is clear: a large number of higher education institutions are now accepting students from a much wider range of academic backgrounds than was formerly the case. Our focus lies in the domain of mathematics, and while we are unclear whether or not mathematics is typical of other subject areas, 
we do know that it can hardly be immune from the broader trends outlined above: Kitchen (1999) presents statistics which clearly document the changing profile of entrants to mathematical sciences in higher education. Broadly, this essay focuses on issues of transition and how these might be influenced by this changing profile. We begin by reviewing what is known about mismatches between school and university mathematics and then seek to link this discussion with a consideration of changes in post-16 education.

Our analysis draws on two main data sources. First, we reviewed a range of documents and literature to trace developments and identify trends in post 16 mathematics. Second, we conducted over a period of six months a small (and informal) case study of a mathematics department of a research university (which we call University X) to provide illustrative data of our developing ideas. The department in question began a steady rise in the numbers of applicants from 1994, due apparently to better publicity, more active recruitment, and, most crucially, the greater number of joint degrees on offer. In fact numbers increased at a regular rate over the last few years from about 55/60 to 120 and this number reflected a rise in those taking joint honours or mathematics major, with the number taking single honours mathematics remaining more or less constant. This increase was in line with the national trend of increasing numbers entering higher education. However, it is one of a handful of leading research universities, and we are unable to assert that it is typical of the situation currently pertaining in universities. On the other hand, by working in a strong department with highly qualified students, we were at least aware that we were studying a 'best case' and that any mismatches we found might be more acute elsewhere (although we cannot rule out the possibility that 'top' students' difficulties arise from different causes than those of the less able).

We set out to explore through interviews with lecturers and students the implications of changes in recruitment on issues of transition from school to university. Our case study was not intended to be systematic (i.e. it did not involve random samples or detailed qualitative analysis) but rather sought data to inform and illustrate our developing analysis. We begin by reviewing recent work which has sought to problematise school-university transition in mathematics.

\section{The transition between school and university mathematics}

For some time, there has been a considerable wave of disquiet concerning schooluniversity transition within the mathematics community. Much of this has been based on personal experiences of lecturers, and 'common sense' inference about the apparent inadequate preparation of students (see, for example, Sutherland and Pozzi, 1995). At 
the same time, there have been very evident changes in the university curriculum. For example, in a study of single honours mathematics, Kahn and Hoyles (1997) concluded that there were three main areas of curriculum change: a broadening of content in the direction of applications and away from traditional pure mathematics, a reduction of advanced, more specialised formal courses to make way for introductory courses, and shifts in assessment practices towards continuous assessment, guidance through question sequence and calculation at the expense of proof. Kahn and Hoyles also noted that these changes appeared to have been made as reactions to external pressures, rather than as proactive initiatives related to teaching and learning. Clearly the situation is complex and every university has sought to balance competing demands. Nevertheless, it is worth asking whether some issues can be identified that transcend individual cases.

A review of the literature quickly shows that this concern over the transition or 'gap' is by no means new. Here, for example, is Bryan Thwaites characterising what in 1961 was, 'being said and thought in universities throughout the country':

...the students do not understand the mathematical ideas which university teachers consider basic to their subject; they are not skilful in the manipulative processes of even elementary mathematics; they cannot grasp new ideas quickly or at all; they cannot write simple English clearly and grammatically; and, particularly, they have no sense of purpose that is, they do not seem to realise that in order to study mathematics intensively they must work hard on their own trying to sort out ideas new and old, trying to solve test problems, and so on. (Thwaites, 1972, p.5)

Later, Bibby (1985) suggested that very few students had developed a critical understanding of mathematics on leaving school and, unsurprisingly, those who had done so stood a better chance of coping at university. Similarly, Cox (1994) argued that the replacement of depth by breadth at school has resulted in poor retention of Alevel mathematics, even by those studying mathematics in their first year at university. More generally, Micallef (1997) has argued that A-levels which forfeit depth in order to provide breadth do not challenge those who are most competent at mathematics.

The issue of the gap between content and expectation of school and university mathematics has been much in the news in the U.K., reflecting an increasing concern that this gap may have widened. One celebrated view of these effects was proposed by the London Mathematics Society, who, in their report, Tackling the Mathematics 
Problem (1995) made some disturbing claims. The report identified three key areas seen to be lacking in mathematics undergraduates at that time:

Students are hampered by a severe lack of essential technical facility in particular a lack of fluency and reliability in numerical and algebraic manipulation and simplification (ibid., para 4a)

Compared with students of 1980 there is a marked decline in students' analytical powers (ibid., para 4b)

Most students entering higher education no longer understand that mathematics is a precise discipline in which exact, reliable calculation, logical exposition and proof play essential roles (ibid., para 4c)

The LMS went on to argue: '...it is not just the case that some students are less wellprepared, but that many 'high-attaining' students are seriously lacking in fundamental notions of the subject. The trend is new, and is a significant indicator that something has gone wrong'. (London Mathematical Society, 1995, p.5).

What has gone wrong? It is tempting to 'blame' the situation on the expansion of higher education - it is, after all, certainly the case that even the most prestigious university departments are digging deeper into the body of potential students than ever before. But this cannot be the whole answer. Research universities have been asking for ever-higher A-level grades from students, and there is mixed evidence concerning the trend in students' mathematical knowledge on entry (the wide range of possible definitions of the word 'knowledge' is partly responsible for the lack of certainty emerging from the findings). Some attempts to quantify the problem are striking: for example, Lawson (1997) claims (based on a single, 'new' university) to have found little difference in performance between those with A-level grade C in the 1997 entry and those with A-level grade $\mathrm{N}$ in the 1991 entry. Others blame changes in school practices such as modular examinations (Taverner, 1997), or a focus on individualised learning (Sutherland, 1998). Nevertheless, studies such as these vary considerably in methodological approach, and it is still not clear just what has and what has not changed (for better or for worse). Our own approach to the problem is to consider what is actually learned in school and university, and to view any mismatches in conceptual rather than only sociological or attitudinal terms.

Before we proceed, we should mention that problems of transition from school to university mathematics is not by any means confined to Britain. De Guzman, 
Hodgson, Robert \& Villani, (1988) compared various countries' approaches to mathematics teaching and concluded that not only are the epistemological and cognitive difficulties at university level apparent internationally, but also that there are widespread sociological, cultural and didactical changes which have taken place though clearly not at the same pace in each country. These points are reinforced by Harel and Trgalova (1997) who highlighted the uniformity in course management across several countries, and like the LMS in the U.K., suggested that students placed less value on value rigour and precision in mathematics than in the past, preferring to calculate intuitively. This growing international concern came to a head in December 1998 in the organisation of a working group of the International Congress of Mathematics Instruction (ICMI) which was called specifically to discuss the plight of undergraduate mathematics, made more acute at a time when student numbers at 'traditional' universities were under threat from distance learning initiatives and private institutions. One outcome of this meeting was a special issue of the International Journal of Mathematical Education in Science and Technology, published in 2000. The papers published in this volume serve as a valuable resource in their focus on teaching and learning at undergraduate level. Our approach here is rather different. We attempt to identify the broad trends that have shaped transition from school to university which, though focusing on data derived from the situation in the U.K., raise issues of concern a wider international community.

In the following sections, we look more closely at some general changes that have taken place and their influences on the learning and teaching of mathematics at university level. First we review what many have viewed as a fundamental conceptual divide between school and university mathematics. We then examine in more detail two general changes in U.K. post-16 education which provide clues around which to structure our discussion of issues of transition, namely the trend to a utilitarian higher education, and the trend to broaden the appeal of A-level mathematics.

\section{The conceptual gap between school and university mathematics}

There is a substantial volume of research which has itemised various components of the a mismatch between school and university mathematics and there is no shortage of material which specifies - sometimes in lurid detail - the full gamut of topics that mathematics undergraduates do not know much about: some examples are calculus, (Ferrini-Mundy and Graham, 1994), set theory, (Hood Baxter, 1994), proof, (Simpson, 1995) and more generally, (Lithner, 2000). Even in Japan, a country that performed well in international comparisons of mathematics achievement, there are reports about the problem and how it might be intensifying. A questionnaire sent to 
departments of mathematics at Japanese universities by T. Nishimori and Y. Namikawa in 1995 to probe impressions of their undergraduates' mathematical abilities (University Basic Mathematics Education Working Group Number 6, 1996) found $78 \%$ of the respondents reporting that the mathematical ability of students was declining, although there was some disagreement as to when the decline started, with $38 \%$ suggesting the 1980 s and $31 \%$ locating it in the 1990s. The main problem areas identified were a lack of mathematical thinking (i.e. the ability to think abstractly or logically and to do proofs), weak calculational competence and the students' lack of 'spirit', an attempt at translating into English an idea connoting motivation and perseverance. The reasons given for the decline overlap with those identified in the U.K., perhaps the most relevant being rote learning, general trends in society and the increase of student numbers.

In the US, Seldon, Seldon \& Mason (1998) have illustrated how poorly students cope with non-routine questions and how they tend to fall back on school strategies whenever they can. This is supported by the work of Anderson, Austin, Barnard \& Jagger (1998) in U.K. who illustrated how little final-year students had tended to absorb of the introductory work of their degrees.

One of the major sources for considering these issues over the last decade has been the literature on 'advanced mathematical thinking', (see, for example, Tall 1991). This work is at pains to highlight what is distinctive about post-school mathematics, and has focused particular attention on the role of definitions, abstract formalisms and proof. Indeed, Nardi (1996) has suggested that the gap between school and university mathematics could be characterised simply as a jump from empirical to abstract mathematics, from the informal to the formal. This points to a qualitative difference between school and university mathematics and implies that if students are to succeed, they have to learn an entirely new way of thinking and operating mathematically. Nardi argues that on arrival at university most undergraduates have little idea of what mathematics is, and assume that it is merely an extension of school mathematics. They are therefore not prepared for the rigour and precision of university mathematics, and the requirement to make connections and abstractions rather than learn sets of recipes.

In this sense at least, university mathematics contradicts much of what is learned in school, leading to confusion and loss in confidence if the two systems cannot be reconciled:

They [students] are cognitively torn between what they instinctively know as a powerful way into mathematical insight (intuition) and their 
desire to be accepted in the culture of mathematical formalism (Nardi, p.289).

It would seem, therefore, that students' difficulties and 'shortcomings' are welldocumented and widely accepted. There is little evidence that the conceptual divide between school and university mathematics is new, or that difficulties are experienced only by those who would not, before the expansion of higher education, have attended university.

It does seem reasonable to conjecture that the changes in recruitment to higher education has had implications for transition from school to university, but it is not obvious what they might be. In order, therefore, to make sense of this situation, we have to link a discussion of the kinds of mathematical knowledge that students experience at different stages of their education with a consideration of the broader trends in higher education together with particular changes in post-16 mathematics education.

\section{The trend to a utilitarian higher education in the U.K. and its effect on mathematics}

Gumport (2000) agues that the last 25 years have seen a reorganisation of universities 'along a utilitarian trajectory' (p. 68). The utilitarianism she describes in ideological terms: in the US at least, the dominant legitimating idea of public higher education has changed from being seen as a social institution (preserving a broad range of social functions) to that of an industry (in which quasi-corporate entities produce a wide range of services in a competitive marketplace).

Used in this sense, the term utilitarian points towards a shift in student expectations of what a degree in mathematics is for (this sense contrasts with other, more philosophical senses: see, for example, Ernest 1991). In fact, this shift mirrors a tension that is present in mathematics itself, between the utilitarian pressure on mathematics as a service subject for other subjects, such as engineering or economics, and the requirements of mathematics as a discipline in its own right (this tension has been discussed, see for example Bibby, 1985 and Noss, 1999). Our conjecture is that the trend towards studying mathematics only or mainly as a tool has become particularly intense in the past few years in the U.K. for several reasons. First, there is the new prevailing culture in universities suggested by Gumport and others. Second, successive governments have guided higher education to concentrate on 'transferable' skills at the expense of knowledge domains per se. Third, there has been an attempt to enhance the status of vocational qualifications which has inevitably shaped students' expectations of education in general. For mathematics, it has meant that more students 
are now taking some mathematics courses post-16 (many under the umbrella of Key skill, application of number) attracted by the perceived view of prospective employers that any mathematics qualification is better than none.

On the face of it, this is a welcome development. But if we focus on A-level mathematics an interesting picture emerges. Heard (1998) highlighted how, in 1965, 43200 people took single A-level mathematics in England and Wales with 15600, or some $36 \%$ of these taking double mathematics. The figure for single mathematics had risen to 69500 in 1990, but with only 6900 , or just under $10 \%$ taking double mathematics. In 1997, the single mathematics figure had declined a little to 61800. However, taking account of the new AS level mathematics (which did not exist in 1990) a total of 71800 students were studying mathematics post-16, with $12 \%$ taking double mathematics.

Even without taking account of the changes in numbers of post-16 students, or demographic differences, the picture emerging from the data is that the absolute number of A-level passes in mathematics is lower than in the 80's with the number of students taking single mathematics remaining relatively stable. Meanwhile, the number taking a second mathematics A-level has declined dramatically (see Wolf, 2000; Kitchen, 1999). In other words, there are proportionally more A-level mathematics students who choose to study mathematics simply as part of a general education, in combination with a range of other subjects. Additionally, we know that less than half of the students with a 'double' award in mathematics go on to study for a degree in mathematics, physics or engineering at university (Brown, 1995; Kitchen, 1999) and the number of students opting to take single honours mathematics at university has remained roughly constant, so that a single A-level mathematics increasingly had to serve as an entry to undergraduate study in the mathematical sciences.

It is reasonable to conjecture that the utilitarian trend in mathematics has been accelerated by the attractive and new lucrative job options for students who study Alevel mathematics. In the U.K, the shaping of A-level mathematics to fit as a useful part of general education has also been further intensified by the way the examination system operates. Examinations are organised by examination boards who compete for students in order to obtain fees. To improve student numbers, the boards have tried over the years to change the image of the mathematics they offer as part of a drive to make it more attractive. For example, the aims and objectives presented by the Associated Examining Board advertise topics such as data handling as more relevant 
to 'daily life', and include the history of mathematics, apparently in an attempt to make mathematics more interesting and popular ${ }^{1}$.

We see, then, that mathematical study has been rendered more accessible than it has ever been, and any discussion which centres on the difficulties and problems this has thrown up, must start with a recognition of this (surely encouraging) reality. It is inevitable that this has changed the way in which many - and perhaps most people view mathematics. One important source of tension, therefore, is that those who are responsible for teaching the subject remain, almost by definition, those who are interested in mathematics as a discipline. The trend to more utilitarian, careeroriented expectations seems inevitably to lead to a mismatch between the expectations and aims of undergraduate mathematics students and their lecturers.

If we take a particularly disputed area of mathematical study, that of proof, we can begin to see where this might lead. We know it is hard conceptually to understand and construct a mathematical proof. How much harder if one rejects - or at least sees no point in - the idea of proving as the crucial characteristic of the mathematical enterprise? (For more information, particularly on the appreciation of proof among new undergraduates, see Anderson, 1996; Jones, 2000).

What mechanisms are responsible for this change - not only in expectation, but in the subject itself? We believe that a good place to start to find out is to examine changes in A-level mathematics, some of which, as we have mentioned, have been put in place in an attempt to increase the popularity of mathematics. This has had rather peculiar consequences which we now discuss in more detail.

\section{The trend to broaden the appeal of A-level mathematics}

When A-level was introduced in 1951, its specific aim was to provide a way to discriminate between university applicants. Since that time, the aims of the examination have changed greatly. Up until the expansion of the University sector in the early nineteen-nineties, it was increasingly the case that many students who chose to continue studying after compulsory education did not choose their A-levels with the sole intention of entering a university degree. Since the massive expansion and more important still the diversification - of the university sector, the situation has become more complex, with students once more seeing A-levels as an entry route to

\footnotetext{
${ }^{1}$ This trend is, incidentally, convergent with changes in the ways mathematics is perceived throughout the school system: it has acquired the label of 'numeracy', and is in some quarters synonymous with it: see Noss, 1996 for a critical view of this development.
} 
university education, but with a much more heterogeneous set of goals and expectations.

Additionally, over the last 5 years there has been a move from the terminal A-level examination, with the whole A-level course being examined at the end of two years' study, to a system of modular A-levels (of the eight examining boards that offered Alevel mathematics, 7 offer modular A-level according to Taverner, 1996, p.38). This has led to much greater flexibility in A-level syllabi and greater teacher/school autonomy in deciding what they would like to teach. In addition, in order to widen choice within syllabi, there is also greater choice between examination boards, more so now since the policy of schools having to pay registration fees to each examination board they use has been abandoned (Taverner, 1996, p.38). This opportunity has, in turn, led to even more competition between boards to make their examinations and syllabi more attractive. The publication of league tables has done little to mitigate these changes.

Alongside these shifts in aims for mathematics provision at A-level and the introduction of modularity and increased competition, there has also been a major change in structure. Given the perceived importance of mathematics, it is perhaps surprising that there has been rather little, if any, research which has tracked the history of this significant change. Below, we briefly provide an outline.

When A-levels were introduced, students interested in mathematics had the choice between taking either pure mathematics as a single qualification or pure and applied as two separate A-levels. The applied material could be mechanics or statistics, with mechanics much the more popular choice. The 1960s and 1970s saw the gradual introduction of Further Mathematics and a shift from two A-levels of equal difficulty (Pure and Applied) to a hierarchical ordering of A-levels of different difficulty (Pure and Applied Mathematics A-levels and Further Pure and Applied Mathematics ALevels). We endeavoured to discover the incentive behind this change from a vertical to a horizontal division of A-level mathematics provision.

Having found no general review, we informally interviewed several individuals with experience of one or more examination boards during the 1960s to the present day, and we also spoke by telephone to representatives from four major boards. What emerged was a picture of unplanned evolutionary change in A-level mathematics provision driven by market forces rather than strategic vision. None of those interviewed had a clear idea of the reasons underpinning the various changes, other than the hope that the board would attract more candidates or that they had reacted to 'teacher pressure'. We were unable to locate any person or institution who had 
maintained an overview of the changes as they had occurred and considered the implications for mathematics provision across the country. On the contrary, it appeared that increasing market share of examination fees was almost the only arbiter: one board's success in increasing numbers resulted in other boards following suit. Given this apparently anarchic situation, it is worth outlining briefly some examples of the changes made and the reasons for them.

NUJMB (Northern Universities Joint Matriculation Board) changed to mathematics and Further Mathematics in 1961, although we were unable to trace any record of why this was done. A sentence in the NUJMB annual report of 1961 states that: "The revised syllabus has gone a considerable way to correct some of the previous problems', but these problems are nowhere discussed.

One year later SMP (School Mathematics Project) decided that asking pupils to take 2 of their 3 A-levels in mathematics was forcing them to overspecialise:

Our opinion is that the present custom of examining mathematics carries strong disadvantages. It encourages over-specialisation in the sixth-form which we are most anxious to combat; we also wish to delay as long as possible the pupil's moment of decision upon his [sic] specialist subjects which the double-subject inhibits. [...] Therefore the School Mathematics Project has resolved to adopt a single-subject treatment at A-level, and not to propose a syllabus for a double-subject examination.' (in Thwaites, 1972, p.42)

SMP carried out a survey to discover whether universities would accept students on a mathematics degree if they had only single mathematics A-level. The majority of universities replied that they would, although worries were expressed that students might 'lack manipulative skill' (p.60), and that 'the average sixth-form boy or girl [...] will not, if this is treated as a single-subject, absorb enough mathematics to be able to embark on our three-years Honours course with any confidence of success [...] there is again conflict between breadth and depth of treatment in the time allotted to the teaching of a single-subject' (p.61). As a result, SMP ended up retaining Further Mathematics as 'an interim measure' (p.62). This 'interim measure' has continued for nearly 40 years, although the numbers taking the examination in all boards has consistently declined over the last decade (see Kitchen 1999, for detailed data).

The story in other boards is consistent with this pattern. ULEAC (University of London Examinations and Assessment Council) have had a Mathematics/Further 
Mathematics distinction for at least the last 14 years, and similarly, MEI (Mathematics for Education and Industry) introduced Further Mathematics in 1985. The Cambridge board also changed in the nineteen-eighties, as a response to the decline in those taking mechanics A-level (more students chose statistics): the board hoped to stem the flow of candidates away from mathematics by offering them a single mathematics Alevel which included either mechanics or statistics, combined with pure mathematics. As far as we can tell, AEB (the Associated Examining Board) was the last board to offer a Further Mathematics A-level, delaying their offer until 1996 when they introduced modular A-levels.

The competition between examination boards was mutually reinforced by the drive from schools to boost their examination successes, particularly since the publication of league tables of results. It is interesting to note that in a survey of secondary schools with sixth form colleges in two local education authorities in the North of England in $1997,90 \%$ of those who returned the questionnaire had changed the examination board used for mathematics A-level since 1989 (Taverner, 1996 p.38). All the changes were in favour of a modular form of assessment. The main rationale for effecting this change was to improve results, though the production of new texts books and a hope of increasing recruitment were also important in the decisions. Taverner comments that among teachers:

Generally the consensus was that recruitment had increased, the dropout rate had decreased and there was evidence of increased motivation and, more importantly, improved mathematical understanding among students (ibid., p.39)

In summary, A-level mathematics is fulfilling a new role as an accessible part of general education. It has achieved this by taking on a modular structure with more choices for students and by making a horizontal rather than vertical division between two mathematics A-level provision, with only a small and decreasing percentage of students taking the Further Mathematics option. But how have modularity and broadened accessibility changed the conceptual nature of school mathematics? Where does single A-level mathematics stand as an entry requirement for future study of mathematics at university? What are the implications of these trends on student competence, expectations, and reactions to undergraduate study? We now turn to a consideration of these issues. 


\section{Implications for the study of mathematics}

In this section, we introduce some of the data gathered at University $\mathrm{X}$, in order to help us assess the implications of the trends identified earlier. We organise our argument under two headings: the first comprises a discussion of single A-level mathematics as a basis for undergraduate study, and the second expands on the division between undergraduate mathematics students holding single or double mathematics A-level entry qualifications.

\section{Single A-level Mathematics as a basis for undergraduate study}

As we argued above, it is increasingly the case that students will go on to study mathematics at university having studied only one A-level in mathematics. It goes without saying that such a student has experienced much less mathematics than those with two A-levels. But the effect of the changes towards a modular structure has resulted in quite a radical shift in curriculum. While some of these alterations have concerned shifts of emphasis, particularly in terms of processes, skills and expectations, others have involved a reduction in the compulsory pure mathematics content. For example, there has been a gradual removal of much vector-based work and complex numbers, the gradual disappearance of geometry and the inclusion of data handling and estimation (see Kitchen, 1999). While discussion of the core knowledge continues and changes are ongoing, it would be surprising indeed if all these changes had no effect. The question is how critical are these (and other) content elements that have been removed to further study in mathematics? Are they crucial in making sense of the mismatches we are trying to understand?

We have some grasp of the implications of the content changes from the comments in our interviews with members of University X's mathematics department. It is fair to say that the lecturers we interviewed had little knowledge of any differences between examination boards. This might seem surprising from an outsider's perspective as these differences are sometimes substantial. But they apparently have little impact on undergraduate study. Unsurprisingly, all agreed that a background of two mathematics A-levels provided a greater level of knowledge, and this was felt to offer a substantial advantage in the first year. We heard the general view that good students would overcome the lack of a second mathematics A-level by the second year. However, there was also agreement that although students who had taken two mathematics Alevels had covered more topics, their attitude towards mathematics and their mathematical ability was not significantly different from that of the single mathematics entrants. The responses included two other common features. First, a 
resignation to the removal of specific mathematics topics from the school curriculum, none of which caused major concern. Second, a genuine worry about students' 'lack of stamina' and manipulative skill. At first sight these seem to be separate issues, the first concerned with mathematical content, and the second, related to a more nebulous, but nonetheless crucial mathematical "habits of mind" (for a full discussion of mathematical habits of mind, see Cuoco, Goldenberg, Mark, 1994). We suggest, however, that there is an intimate connection.

In terms of content changes, the change in focus of mathematics A-level with its greater emphasis on the more practical, and allegedly enjoyable side of mathematics has provided the rationale for excluding areas such as geometry and complex numbers and conversely, for including topics such as data handling. We surmise that this has had two effects. One is obvious: students often do not have the experience and skills expected by their university teachers. But there is a second and no less important effect. We argue by example. If a student is not familiar with geometry, then it is much more difficult to see key properties of, say, complex numbers or differential equations. So the gaps in knowledge become not just the lack of bricks, but the gradual disappearance of the cement which holds them together. Studying mathematics with statistics but without mechanics may introduce students to important stochastic ideas which have played such a crucial role in twentieth century natural and social science. But it may also (at least as statistics is currently taught) reduce the scope for seeing beyond individual elements to the bigger mathematical picture which is so important at university level (and so difficult to teach). Similarly, there are certain pieces of mathematical content which have traditionally provided an arena for practising proof, and it is these which have gradually disappeared. Not surprising then, that the downplaying of proof in A-level seems certainly to be one of the key absences identified by the university teachers, and one of the most obvious deficiencies felt by those students who had not explicitly encountered it.

In fact, we have data from our case study that add some weight to this point, in the form of interviews with students with different backgrounds at A-level which leads us to explore further the experiences at university of students with one or with two Alevel mathematics passes.

\section{The Mathematics/Further Mathematics divide}

Our student interviews allowed us to draw out some interesting ramifications of the change in structure of A-levels from a horizontal separation of two mathematics courses at approximately the same level of difficulty, to a vertical arrangement Mathematics and Further Mathematics — of rather different levels of difficulty. As 
we stated earlier, there has been a marked reduction in the number of students taking Further Mathematics. It is regarded as hard, many schools (at least state schools) do not have the resources to teach it because of the small numbers involved or because of the difficulties in finding a suitably-qualified teacher, and it is not in any case an entry requirement for mathematics courses in the majority of universities. Against the trend, over $50 \%$ of applicants to University $\mathrm{X}$ had studied 'A' or 'AS' level Further Mathematics (we are unaware of any current way of accurately assessing what 'fraction' of an A-level an AS actually comprises, although the official line is that it represents half). We were, however, unprepared for the extent to which this difference was felt so strongly by the first-year students we interviewed.

At the risk of overstating our findings, we feel we should highlight the extent of the negative feelings expressed by those who had only studied a single mathematics Alevel, all of whom expressed the belief that they were at a disadvantage and more likely to struggle. One student, when asked if she thought that anyone was coping with the mathematics at university replied:

Yeah. Further maths students and geniuses!

Several students suggested that Further Mathematics and A-level mathematics students should not be taught together on the introductory course as this meant that some topics which were new to 'single A-level' students, were introduced too quickly. Additionally, in the first year of the course, as tutorial groups (which our interviewees identified as the most useful way of learning) were simply divided alphabetically, students could see that those students with Further Mathematics were struggling much less than the single maths students. One student suggested that these tutorial groups should also be divided between those who had and had not done double mathematics as this would make it easier to ask questions:

I am so ashamed to ask simple principles to double mathematicians because I just show myself up all the time. I would feel much more comfortable with a group of single mathematicians, yeah, who basically know the same amount as I do and are struggling in the same sort of way.

The strength of the feelings of inadequacy expressed by those with one A-level as they compared themselves with the Further Mathematics students was surprising. It underlined once again how much of an advantage Further Mathematics was seen to be by students, even though the lecturers as we have noted earlier found it much less important. We suggest these sentiments expressed a clash of expectations and 
objectives on the part of students and tutors. Those without Further Mathematics tended to locate their difficulties in terms of not knowing subject content rather than a lack of familiarity with a rigorous approach. Their tutors, on the other hand, were relatively unconcerned about their lack of knowledge, and much more attuned to the problem of getting students to think mathematically.

We add another surprising finding from our interviews, relating to school organisation following the change to a horizontal division of the two mathematics A-levels. We discovered that all but one of the schools attended by our student-interviewees taught those taking mathematics and Further Mathematics in different A-level classes from those taking single mathematics A-level. Thus, the way these classes were typically organised seemed to operate a type of setting process, separating 'the best mathematicians' who definitely wanted to go on to study mathematics (or a related subject) from the rest - and the rest would include students who were taking mathematics simply as one of their A-levels as well as those who might in fact read mathematics at university. Our conjecture is that this practice is quite widespread as a way of mobilising scarce resources in schools. It would seem likely, however, that this 'setting' of students would have considerable effects on the teaching of the single Alevel subject - how the teacher would introduce topics, present challenges and share expectations, and at the same time would substantially influence students' selfperceptions. Perhaps it is not so surprising, then, that students felt a stigma attached to their lack of Further Mathematics A-level - they had learned in school that they were not in the top bracket of mathematics achievement.

The Further Mathematics issue should not, however, be taken out of context. University $\mathrm{X}$ is not unique, but it is not typical. Unlike other universities, many students at $\mathrm{X}$ have studied double mathematics, and the course is very demanding. Yet many of the commonly-expressed complaints one hears among mathematics lecturers concern students who do have good double mathematics grades, and yet still apparently harbour surprising views about mathematics from which their predecessors are alleged to have been free. It seems clear that there are complex issues regarding teaching, learning and assessment that would have to be considered before any definitive picture could be drawn: we cannot discuss these here (some of these have recently been aired in Measuring the Mathematics Problem, 1999).

\section{Some conclusions}

Mathematics has always had two faces. It is a tool in the study of the sciences, and it is an object of study in its own right. In the past, many - though surely far from all - students saw the latter face, and found it attractive. Most, perhaps all, of those 
teaching in mathematics departments today, think of mathematics this way. Yet in the late 1990s, a substantial number of students are attracted by the other face of mathematics, attracted to study the subject for a multitude of reasons (generic skill, apparent 'ease' at school, perceived fit with future employment) which, however legitimate, do not necessarily accord with the aims or the culture of those who teach them.

In this paper we have pointed to a variety of reasons which may help to explain how the two faces of mathematics have become ever more educationally distinct. Fuelled by competition between examination boards and the publication of league tables, this disparity has become more institutionalised in the study of two horizontally separated A-levels which frequently means the physical separation of students into those who are allowed to see both faces, and those who are not. This latter group - particularly though not exclusively - arrive at University only to be confronted with a subject they do not recognise. Mathematics is certainly difficult and university mathematics has always stood out as a subject for which school curricula offer only weak preparation. Now more than ever, little in the school experience of single A-level prepares a student for what he or she might meet in a traditional mathematics course. Many would argue that 'Further Mathematics' might partially redress the balance. Yet the massive decrease in the numbers of those taking it has led to some very negative feelings of inadequacy on the part of the majority who do not ${ }^{2}$.

It is easy for those whose professional life centres around the doing or teaching of mathematics to lament this state of affairs. We should, after all, remember that there is a positive side as well. For without doubt, the absolute numbers and proportion of students studying mathematics at A-level and beyond has increased, and there is little doubt that this would not have been feasible if the structures and approaches of the subject at school had remained targeted only at those who required to study mathematics as a theoretical discipline. This new constituency has responded to the broadening of the curriculum and the sacrifice of depth which has accompanied it. On the other hand, there are, for mathematicians and scientists of all kinds, serious implications if mathematics is in the process of being reconstructed as an theoretical subject, where the empirical, calculational elements which characterise school mathematics are elevated at the expense of the theoretical and abstract and to the extent that proof plays at most an auxiliary role.

\footnotetext{
${ }^{2}$ At University $\mathrm{X}$, as we have explained, the single/double entry split was about equal. But overall, it must of course be heavily in favour of single mathematics entrants.
} 
We argued earlier that this is not simply a question of the disappearance of particular knowledge elements such as geometry or complex numbers, or the downplaying of algebraic and trigonometric manipulations. Changes in content have engendered changes which constitute more than the sum of their parts, a shift in the ways that students are able to piece together what the subject is about. We suggest that whatever the pros and cons of changes in content (and there are, for example, some very good reasons for including more statistics than was usual a couple of decades ago) they are part of a more complex web of amendments and omissions which may have led to unpredicted conceptual problems for students. If mathematics is presented as a collection of topic fragments where each is represented by some sort of definition (maybe only a name) and a set of algorithms, then students may never see the depth in a particular topic and understand how this might link up to other areas. If there is not exposure to a subject in depth then the level where topics interlink may never be reached and flexibility necessary for manipulation might be all the more difficult. If proof has been largely removed from single A-level, how can it provide conceptual glue for further courses and how can students develop mathematical "habits of mind"?

There are changes which the mathematical community must face, and these are often taking place in domains outside our control, for example at the level of government policy. The demands for directly employable skills or key competencies is leaving little room for a subject whose raison d'être is the establishment of truth from axioms and deductive logic. There is an irony in the situation. For it is arguably these latter facets of mathematics which lend it its currency as an entrée into the dealing rooms, software houses and other lucrative consumers of mathematical expertise. In the understandable rush to broaden the appeal of mathematics, it stands in danger of losing just those higher-order attributes that are recognised as special in the world of work and in other subjects.

We conclude by summarising our findings in the form of a research agenda. The first item stems from the observation that A-level mathematics is no longer purely designed as a tool for serving the needs of university mathematics. This implies the need to turn our attention to how universities can work with the skills that many of today's undergraduates possess, including recognition of the new skills they have acquired. Many universities, including $X$, are trying to do just this. Most of their students, it seems, do overcome the problems initially faced when entering the university, and it would be useful to examine how these students and their teachers achieve this success. We conjecture, however, that this is - as we stated earlier - a 'best case' scenario, in which gifted students with highly qualified staff may work together effectively to overcome the initial difficulty. 
It would be interesting to examine further the real or apparent divide between A-level and Further Mathematics students in broader (and perhaps more typical) contexts - we would need to take account of the reality that there are many institutions where very few students have taken Further Mathematics courses at all. The fact that school mathematics is so different from university mathematics, and that tutors recognise that there is a jump ${ }^{3}$, implies that the change in content at A-level may play less of a role than we think in determining the facility with which students make the transition. Further investigation therefore needs to concentrate on what exactly is being lost (and gained?) due to the changes in A-levels and how students can overcome this. A first step would be to chart the evolution of students' mathematical experiences at university and seek continuities between their emerging understanding of mathematical ideas and those they have on entry.

Secondly, the implications of the utilitarian trend need to be examined. Does this trend inevitably mean that mathematics at school and at university must concede its theoretical face to most, if not all, its potential students, leaving the most mathematically gifted to other disciplines? Perhaps so, but this surely is a research (and policy) issue rather than one which we should take for granted. Should we, in any case, take for granted that mathematics as a tool can or should be studied effectively without the fundamentals that underlie it (see Noss, 1999, for a discussion of just this issue regarding service mathematics)?

A third item concerns the distortions of curriculum and mathematical culture that seem to have flowed directly from the market economy in examination syllabi and approach. We need to trace over time the effects of examination changes and this is by no means straightforward. For example, it is reasonable to hope that the switch to modular courses could take place alongside a trend in favour of independent study certainly there is nothing in the former which rules out the latter. But in the absence of some co-ordinated and concerted direction, that is unlikely to take place. Similarly, in terms of domain knowledge, we urgently need to know what the cumulative effect of various omissions and insertions has been, in terms of influencing students' chances of gaining a coherent picture of what mathematics is about. Such a view would lead us to reject simplistic but fashionable 'solutions' such as reinstating the curriculum of thirty years ago, or returning to an elitist vision of who should study mathematics and why.

\footnotetext{
${ }^{3}$ One lecturer put it to us like this: "...people go on perfectly happily for a long long time and then suddenly they reach a point when they can't understand a single thing. This is not just a feature of the way maths is taught, to some extent this is what maths is like. If you want to understand the hard stuff, it's hard, and so all that combines to mean that maths at university is a bit of a surprise".
} 
On the contrary, it would enable curriculum planners to gain a more coherent view of what mathematical skills and knowledge are essential to modern mathematics-based study, and learn how to incorporate these into twenty-first century curricula which cannot continue indefinitely to be based on the mathematics of the nineteenth century.

Fourthly, and perhaps most challenging of all, we would like to know if it is possible for breadth and depth to reach a détente, or whether mutual antagonism is the only possibility: whether, in other words, we can address the problem of accessibility without inevitably destroying the coherence of that which we are trying to make accessible. Discussion of this issue is outside the scope of this paper (but see Kent and Noss, 2000, for a possible way forward which argues that constructive use of digital technologies may assist in this challenge).

The final item of our putative research agenda concerns broadening and formalising the kind of informal study we used to anchor our discussion in this paper. In choosing a leading research university for our case study, we did not expect to encounter students who believed that a mathematics degree was an ideal preparation for being an accountant, or many who had no idea what proof was. But we have relatively little idea what happens in the rest of the University sector. Most students do not have 30 A-level points, and do not attend an institution at the leading edge of mathematical research. The changes of the past two or three decades may have opened mathematical doors which were closed before. We cannot expect student expectations to have remained unchanged - but in identifying their hopes and aspirations perhaps we could narrow the gap between what students expect from a mathematics degree, and what is on offer.

\section{Acknowledgement}

We wish to thank staff at University $X$ for not only giving us generous access to undertake the case study, but also for taking time to comment on an earlier draft of this paper.

\section{References}

ANDERSON, J. A. (1996) The Legacy of School: Attempts at justifying and proving among new undergraduates, Journal of Teaching Mathematics and its Applications, 15,3 , pp. 129-134.

ANDERSON, J. AUSTIN, K. BARNARD, T. \& JAGGER, J. (1998) Do Third-Year Mathematics Undergraduates Know What They Are Supposed to Know? 
International Journal of Mathematical Education in Science \& Technology, Volume 29, No. 3, May-June, pp. 401-420

BIBBY N. (1985) A Study of the Transition in Mathematics From Sixth Form to University, University of Sussex Education Area Occasional Paper 12.

BROWN, M. (1995) Sum Mistake? Times Higher Education Supplement, p.17, 24.2.95

BURN, R. P. \& WOOD, N. G. (1995) Teaching and Learning Mathematics in Higher Education, Teaching Mathematics and its Applications, Volume 14, No.1. pp. 28-33

COX, W. (1994) Strategic Learning in A-level Mathematics, Teaching mathematics and its applications, Volume 13, No. 1, pp.11-21

CUOCO, A. GOLDENBERG, E. P. \& MARK, J. (1996) Habits of Mind: An

Organizing Principle for Mathematics Curricula. Journal of Mathematical Behaviour.

Volume 17, pp375-402.

DE GUZMAN, M. HODGSON, B. R. ROBERT, A., \& VILLANI, V. (1998) Difficulties in the Passage from Secondary to Tertiary Education: Documental Mathematics, Extra Volume ICM, 111. pp. 747-762

DEARING, R. (1997) The National Committee of Inquiry into Higher Education

ERNEST, P. (1991) The Philosophy of Mathematics Education. London: Flamer Press.

FERRINI-MUNDY, J. \& GRAHAM, K. (1994) Research in Calculus Learning: Understanding of Limits, Derivatives and Integrals in: J. J. KAPUT, and E. DUBINSKY, (eds.) Research Issues in Undergraduate Mathematics Learning: Preliminary Analyses and Results, MAA Notes Number 33.

FORGASZ, H. J. \& LEDER, G. C. (2000) Perceptions of the tertiary learning environment: is mathematics worth the effort? International Journal of Mathematical Education in Science \& Technology, Volume 31, No. 1, Jan-Feb, pp. 37-42.

GUMPORT P. (2000) Academic restructuring: organizational changes and institutional imperatives. Higher Education 39: 67-91.

HAREL, G. \& TRGALOVA, J. (1997) Higher Mathematics Education in: A. BISHOP (Ed), International Handbook in Mathematics Education, (Lower Academic Publishers).

HEARD, T. (1998) Encouraging Further Mathematics: Some Practical Issues. Personal communication

HOOD BAXTER, N. (1994) Understanding How Students Acquire Concepts Underlying Sets, in J. J. KAPUT, \& E. DUBINSKY, (Ends) Research Issues in Undergraduate Mathematics Learning: Preliminary Analyses and Results, (Ends) MAA Notes Number 33.

ICMI Study Conference (1998), On the Teaching and Learning of Mathematics at University Level. Pre-proceedings of meeting 8-12 December, Singapore.

JONES, K. (2000) The Student Experience of Mathematical Proof at University Level. International Journal of Mathematical Education in Science \& Technology, Volume 31, No. 1, Jan-Feb, pp. 53-60.

KAHN, P. E. \& HOYLES, C. (1997) The Changing Undergraduate Experience: a case study of single honours mathematics in England and Wales: Studies in Higher Education. 
KAPUT, J. J. \& DUBINSKY, E. (Ends) (1994) Research Issues in Undergraduate Mathematics Learning: Preliminary Analyses and Results, MAA Notes Number 33 published and distributed by The Mathematical Association of America.

KENT, P. \& NOSS, R. (2000) The Visibility of Models: Using Technology as a Bridge between Mathematics and Engineering. International Journal of Mathematics Education in Science and Technology. 31,1,Jan-Feb, 61-70

KITCHEN, A. (1999) The Changing Profile of Entrants to Mathematics at A-level and to Mathematical Subjects in Higher Education, British Education Research Journal, volume 25, No. 1, pp. 57-74.

LAWSON D.(1997) What can we expect from A-level mathematics students? Teaching Mathematics and its Applications, Volume 16, Issue 4.

LITHNER, J. (2000) Mathematical reasoning and familiar procedures. International Journal of Mathematical Education in Science \& Technology, Volume 31, No. 1, JanFeb, pp. 83-95.

LONDON MATHEMATICAL SOCIETY (1995) Tackling the Mathematics Problem.

MEASURING THE MATHEMATICS PROBLEM (1999) Report of a seminar at the Muller Centre, Cambridge. London: The Engineering Council.

MICALLEF, M. (1997) A-levels: A Higher Education Perspective, Warwick University, Math skills Newsletter, Issue 4, July 1997

NARDI, E. (1996) The Novice Mathematician's Encounter With Mathematical Abstraction: Tensions in Concept-Image Construction and Formalisation, DPhil, Linacre College, Trinity Term.

NISHIMORI, T. \& NAMIKAWA, Y. (1996) Is the Mathematical Ability of University Students Declining? Report of the Investigation Questionnaire University Basic Mathematics Education Working Group, Report Number 6, translated by Thomas Judson, available from: oc/wg-homepage.html.

NOSS, R. (1997) New Cultures, New Numerations, An Inaugural Lecture, Institute of Education, University of London.

NOSS, R. (1999) Learning by Design: Undergraduate Scientists Learning Mathematics. International Journal of Mathematics Education in Science and Technology. 30 (3), 373-388

ORMELL, C. (1997) Mathematics and the School Crisis, MAG News, Issue 31

PITT (1997) A university view on a possible minimal core for 'A' level mathematics, (1977) Standing Conference On University Entrance.

SELDON, J., SELDON, A. \& MASON A. A. (1994) Even Good Calculus Students can't Solve Nonrountine Problems, in Research Issues in Undergraduate Mathematics Learning: Preliminary Analyses and Results, J. J. KAPUT, and E. DUBINSKY, (Eds) MAA Notes Number 33.

SIMPSON, A. (August 1995) Focusing on Student Attitudes to Proof, Teaching \& Learning Undergraduate Mathematics (TALUM) Newsletter no. 3, pp: 1-4

SUTHERLAND, R. \& POZZI, S. (1995) The Changing Mathematical Background of Undergraduate Engineers, The Engineering Council, March

SUTHERLAND, R. (1998) Algebra and symbol sense in the formation of engineers. Teaching Mathematics and its Applications, Volume 18, Issue 4, pp. 179-184 
TALL, D. (Ed) (1991) Advanced Mathematical Thinking, Kluwer Academic Publishers, Dordrecht.

TAVERNER, S. (1996) An Investigation into the A-level entry policy of mathematics departments, British Journal of Curriculum and Assessment, Volume 7, no.1, pp. 3841.

TAVERNER S. (1997) Modular courses - a drip feed approach to teaching and learning? Teaching Mathematics and its Applications, Volume 16, Issue 4.

THWAITES, B. (1972) SMP: The First Ten Years, (Cambridge University Press, London).

WOLF, A (2000) Mathematics for Some or Mathematics for All? Curious U.K. practices in International Context, in The Maths We Need Now: Demands, Deficits and Remedies, C.Tikly and A. Wolf (eds) Bedford Way Papers, Institue of Education, University of London, pp104-137 